\title{
Spotlight on decitabine for myelodysplastic syndromes in Chinese patients
}

This article was published in the following Dove Press journal:

OncoTargets and Therapy

3 October 2015

Number of times this article has been viewed

\author{
Yu Jing $1, *$ \\ Xue Shen ${ }^{2, *}$ \\ Qian $\mathrm{Mei}^{3}$ \\ Weidong $\mathrm{Han}^{3}$ \\ 'Department of Hematology, PLA \\ General Hospital, ${ }^{2}$ Department of \\ Cell Biology, School of Basic Medical \\ Sciences, Peking University Health \\ Science Center, ${ }^{3}$ Department of \\ Molecular Biology, Institute of Basic \\ Medicine, Chinese PLA General \\ Hospital, Beijing, People's Republic \\ of China \\ *These authors contributed equally \\ to this work
}

\begin{abstract}
Myelodysplastic syndromes (MDSs) are a group of heterogeneous clonal hematopoietic stem cell malignancies with advanced median age. The silencing of tumor suppressor genes caused by DNA hypermethylation plays a crucial role in the pathogenesis of MDS. Decitabine, the available hypomethylating agent, is successfully used for the treatment and improves the outcome of MDS, and has become one of the most frequently administered disease-modifying therapies. With an aging population and a growing number of people exposed to benzene, the incidence of MDS has been increasing rapidly. The blinded regimen choice and the lack of a unified strategy create challenges for the treatment of MDS. Here, we present a review of clinical progress and prospects of decitabine treatment of MDS in the People's Republic of China. We also discuss the optimization of therapy issues to improve the cure rate and prolong survival in patients with MDS.
\end{abstract}

Keywords: myelodysplastic syndromes (MDSs), decitabine, hypomethylating agents, People's Republic of China, traditional Chinese medicine

\section{Introduction}

Myelodysplastic syndromes (MDSs) are a heterogeneous collection of clonal hematopoietic stem cell diseases, which are characterized by ineffective hematopoiesis, subsequent cytopenias, and transformation to acute myeloid leukemia (AML). ${ }^{1}$ The morbidity of MDS increased with age. The yearly incidence rate is approximately 4.5 per 100,000 people in the general population, 27.9 per 100,000 septuagenarians, and reaching 51.5 per 100,000 in people aged 80 years and above. ${ }^{2}$ The pathogenic factor of MDS remains obscure, but has been related to the lifestyle and environmental factors. The incidence of MDS is believed to be increasing in the People's Republic of China as a result of the aging population and augmented expose to benzene, which has been confirmed to be a risk factor of MDS. ${ }^{3,4}$ However, because of the unavailability of curable approach and the blindness of strategy choice, clinical practice in the treatment of MDS is forced to face the new challenges in the People's Republic of China.

Current common regimens for MDS treatment include hematopoietic stem cell transplantation (HSCT), immunotherapeutic strategies, chemotherapy, supportive care, iron-chelating therapy, targeted therapies, and so on. HSCT, the only potentially curative approach of MDS, is not applicable to older patients and those without histocompatible donor. Moreover, supportive care, including anti-infection and improvement of anemia/thrombocytopenia/neutropenia, would give rise to blood transfusion dependency, iron overload and impaired quality of life.

The identification of multistage epigenetic modification brings a revolution in understanding of the pathogenesis of MDS. Decitabine, the Food and Drug Administration (FDA)-approved hypomethylating agent, has doubtless improved the outcome and prolonged overall survival of patients with MDS. Noticeably, the elderly patients, 
who cannot tolerate certain types of intensive chemotherapy or HSCT, would probably better fit the decitabine strategy, because of the mild toxicity profile of decitabine..$^{5,6}$

However, the promotion of decitabine as an appropriate strategy for MDS presents many challenges, including the absence of the uniform guidelines for clinical practice and the clinical effect comparison. This article provides an overview of the current clinical role of single or combined decitabine regimens and optimizes therapeutic choices for the treatment of MDS in the People's Republic of China.

\section{Mechanism of MDS treatment with decitabine Decitabine demethylation and molecular mechanism of action}

The efficacy of hypomethylating agents is based on epigenetics. ${ }^{7,8}$ Epigenetics is a subdiscipline of genetics that suggests that DNA sequences do not change, but that gene expression may demonstrate hereditary changes. These changes are caused by changes in other genetic materials rather than in the genetic information carried within a cell, and can be passed on steadily as an organism grows and develops. ${ }^{9,10}$ As this change has been repeatedly detected in the onset of tumors, it has been studied within the mechanism of tumorigenesis, as well as forming an important target for tumor treatment..$^{9,11,12}$

Current studies suggest that the main epigenetic processes include DNA methylation, histone modifications, and noncoding RNA regulation. DNA methylation is the best and most important form of epigenetic regulation. Under normal conditions, in mammalian cells, cytosine is methylated on the fifth carbon atom via DNA methyltransferase DNMT and is thereby converted to 5-methylcytosine. For this process, the primary locus of DNA methylation is $\mathrm{CpG}$ dinucleotide, which is nonhomogeneously distributed in the genome. Regions known as $\mathrm{CpG}$ islands have a density of $\mathrm{CpG}$ sequences of more than 10-20 times the average, a guanine-cytosine percentage that is greater than $50 \%$, and more than 200 base pairs; approximately $50 \%$ of human genes have $\mathrm{CpG}$ islands. $\mathrm{CpG}$ island promoters, located upstream of regulatory regions of genes, are usually in a nonmethylated state in order to ensure normal gene expression. $\mathrm{CpG}$ island methylation affects the transcriptional regulation of the downstream gene, gene expression occurs, and even gene silencing.

Two DNMT inhibitors, decitabine and azacitidine, are approved as hypomethylating agents for the treatment of MDS by the FDA. ${ }^{7}$ These two agents are similar in structure, but play a different role in the mechanisms, although both the agents can alter the pathological process by inhibiting DNMTs. ${ }^{13-16}$ Several comparative studies have suggested that azacitidine is preferred over decitabine based on survival data. ${ }^{17,18}$ However, there still remains a matter of debate to establish the exact role of decitabine compared to azacitidine in the Asian population. Some Asian-specific single nucleotide polymorphisms (SNPs) of the CDA gene (cytidine deaminase) have been detected, and these SNPs would affect the enzymatic activity to inactive decitabine. ${ }^{19-22}$ The genetic characteristics are likely to accrue the indeterminate result of the comparison between decitabine and azacitidine in Asian MDS patients, ${ }^{23}$ and this has been confirmed by several analyses in Japanese and Korean patients. ${ }^{24-26}$ Unfortunately, since decitabine is the only hypomethylating agent approved in the People's Republic of China, the conclusion of Chinese patients is hampered by the paucity of azacitidine data. Thus, we mainly focused on the clinical benefits of decitabine for MDS patients in the People's Republic of China.

\section{The role of decitabine in the treatment of MDS}

Current research indicates that the effects of decitabine on MDS are based primarily on the dose, inhibiting DNA methylation at the low dose and producing cytotoxicity at high dose. ${ }^{27,28}$

In recent years, a number of studies have confirmed that molecular abnormalities in MDS, including the epigenetic processes of DNA methylation and hypermethylation of $\mathrm{CpG}$ islands and gene promoter regions, are associated with the severity of MDS and patient age. So far, we know that hypermethylation causes inactivation of MDS genes, including p15INK4B, p21, the estrogen receptor, CALC1, E-cadherin, HIC-1, RASSFIA, and so on. Using decitabine at low concentrations can substitute for cytosine and DNA methylation in tumor cells metastasis enzyme covalent binding, but cannot induce cell death. Instead, it can reduce the hypermethylation of $\mathrm{CpG}$ islands in patients with MDS and activate methylation by inhibiting DNMT, which will lead to a higher response rate. High concentrations of decitabine, however, can inhibit DNA synthesis, inhibit S-phase cells, induce cell death, and exert a cytotoxic effect. Currently, decitabine is used to treat MDS, mostly at low doses in demethylation treatment (Figure 1). ${ }^{29-31}$

Compared with younger patients who need and can cope with HSCT, elderly patients with MDS and mainly hematological parameters are more suited to treatment with hypomethylating agents. It improves and extends survival 


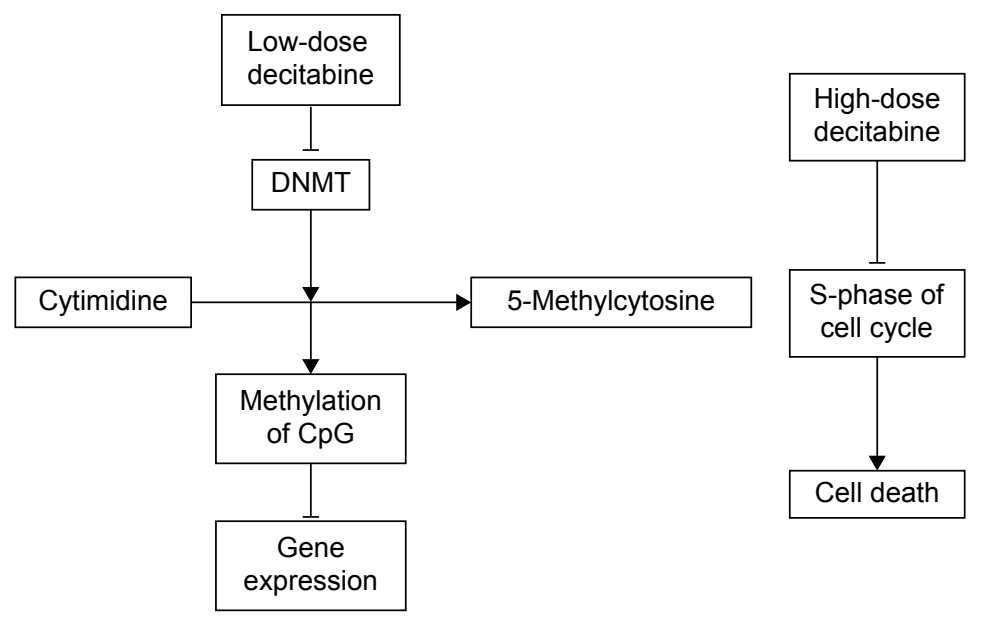

Figure I Mechanism of decitabine in the treatment of MDS.

Abbreviations: DNMT, DNA methyltransferase; MDS, myelodysplastic syndrome.

time, and even in the absence of complete remission, patients have access to these benefits. ${ }^{32}$

\section{Progress in clinical studies on decitabine}

\section{Developments in research on decitabine}

In 1964, decitabine was first developed by MGI Pharma, Inc., Bloomington, MN, USA (with the trade name Dacogen) and took the form of an injection. Work in epigenetics and tumor relationship research has increased till, until in the 1990s, decitabine became part of a new breakthrough. In 1997, Uchida found that $p 15 I N K 4 B$ gene methylation frequencies in high-risk MDS patients were higher than those in patients with low-risk MDS. ${ }^{33}$ Christiansen $(2003)^{34}$ showed that $p 15$ INK4B gene methylation was elevated in patients with acute myeloid leukaemia (AML) and with MDS; ${ }^{35}$ methylation means poor prognosis. ${ }^{36}$ In Phase II clinical trials, the overall response rate (complete response [CR] + partial response [PR]) was $49 \%$, the response rate achieved in high-risk patients being $64 \%{ }^{36,37}$ Phase III randomized clinical trials compared traditional supportive therapy with decitabine (weekly injections for 3 days, for a total of ten periods) and indicated a better overall response rate and quality of life for the latter. For the transfer rate of AML, supportive therapy is 1.68 times higher than decitabine therapy. ${ }^{38-41}$ Methylation studies of decitabine for treatment of MDS provide us with both a theoretical basis and practical experience. In 2006, the European Medicines Agency in Europe and the FDA in the USA gave marketing clearance for decitabine to be used mainly for the treatment of primary and secondary MDS. Decitabine entered the People's Republic of China in 2009 and was approved by the State Food and Drug Administration, being directly listed without the need for clinical trials. ${ }^{42}$ Currently, for decitabine research, the main dosing guidelines apply to use of the medication alone; to the use of a combined regimen with allogeneic bone marrow transplantation; and also to the combined use with other drugs; for example, decitabine may be used jointly as part of a CAG program (aclacinomycin, low-dose cytarabine, and granulocyte-colony stimulating factor [G-CSF]), or as part of a HAG (homoharringtonine, cytarabine, and G-CSF) program. However, to ascertain the best combined program, answers and evidence from clinical testing and research are required. ${ }^{43,44}$

\section{International clinical scenarios relating to decitabine and International Prognostic Scoring System risk scores}

Currently, patients with MDS can be identified through the International Prognostic Scoring System (IPSS; Table 1),

Table I Prognosis of MDS according to IPSS risk score

\begin{tabular}{llll}
\hline $\begin{array}{l}\text { IPSS risk (\% IPSS } \\
\text { population) }\end{array}$ & Overall score & $\begin{array}{l}\text { Median survival }(\mathbf{y}) \text { in } \\
\text { the absence of therapy }\end{array}$ & $\begin{array}{l}\text { 25\% AML progression }(\mathbf{y}) \\
\text { in the absence of therapy }\end{array}$ \\
\hline Low (33) & 0 & 5.7 & 9.4 \\
Intermediate-I (38) & $0.5-1.0$ & 3.5 & 3.3 \\
Intermediate-2 (22) & $1.5-2.0$ & 1.1 & 1.1 \\
High (7) & $\geq 2.5$ & 0.4 & 0.2
\end{tabular}

Abbreviations: MDS, myelodysplastic syndrome; IPSS, International Prognostic Scoring System; AML, acute myeloid leukemia; y, years. 
Table 2 Prognosis of MDS according to revised IPSS risk score

\begin{tabular}{llll}
\hline $\begin{array}{l}\text { IPSS-R risk category } \\
\text { (\% IPSS-R population) }\end{array}$ & Overall score & $\begin{array}{l}\text { Median survival }(\mathbf{y}) \text { in } \\
\text { the absence of therapy }\end{array}$ & $\begin{array}{l}\text { 25\% AML progression }(\mathbf{y}) \\
\text { in the absence of therapy }\end{array}$ \\
\hline Very low (19) & $\leq 1.5$ & 8.8 & Not reached \\
Low (20) & $>1.5 \leq 3.0$ & 5.3 & 10.8 \\
Intermediate (20) & $>3.0 \leq 4.5$ & 3 & 3.2 \\
High (I3) & $>4.5 \leq 6.0$ & 1.6 & 1.4 \\
Very high (10) & $>6.0$ & 0.8 & 0.7 \\
\hline
\end{tabular}

Abbreviations: MDS, myelodysplastic syndrome; IPSS, International Prognostic Scoring System; IPSS-R, Revised International Prognostic Scoring System; AML, acute myeloid leukemia; $y$, years.

the IPSS Revised International Prognostic Scoring System (IPSS-R; Table 2), and the World Health Organization-based Prognostic Scoring System (WPSS; Table 3). The appropriate treatment choice and therapeutic medicines have practical implications. ${ }^{45}$

The overall strategy for the treatment of MDS internationally is as follows. For IPSS risk groups based on patients with low and intermediate-1 risk: treatment mostly consists of stimulating the remnants of the blood-forming capacity of hematopoietic stem cells in MDS and/or controlling abnormal hematopoietic clones, thereby inhibiting progression and improving patients' quality of life; for intermediate-2-risk and high-risk patients, there is a need to eradicate abnormal hematopoietic clones in MDS, and to restore normal hematopoiesis.

National Comprehensive Cancer Network guidelines for the treatment of MDS were divided into low-intensity and high-intensity treatment. ${ }^{45}$ Low-intensity therapy for outpatients is defined as the following: the selection of induced differentiation of hematopoietic cell growth factors, medications, low-intensity chemotherapy, and biological response modifiers. Decitabine and other hypomethylating agents are mainly used for transfusion-dependent therapy, with erythropoietin and other drugs, after the first-line treatment of patients with recurrent or refractory disease requiring follow-up treatments.

IPSS score intermediate-2 and high-risk patients need intensive therapy. This is not the only necessary hospital treatment; intense joint HSCT and chemotherapy are also needed. Although there remain many unmet needs in the treatment, decitabine has become one of the optimal regimens and may favorably influence response rates for MDS patients who cannot undergo HSCT. The treatment program has two phases: the first for $45 \mathrm{mg} / \mathrm{m}^{2} /$ day, three times daily (once every 8 hours), administered intravenously over 3 hours; continuous treatment for 3 days (total dose, $135 \mathrm{mg} / \mathrm{m}^{2}$ ) and the second for $20 \mathrm{mg} / \mathrm{m}^{2} /$ day, vein drops note, drops note time in 3 hours above; continuous treatment for 5 days (total dose $100 \mathrm{mg} / \mathrm{m}^{2}$ ). Four weeks are required for one treatment, with at least four courses of treatment; once the treatment is effective, it is continued. ${ }^{46}$ The latter single 5-day, four-cycle treatment program is the ideal single-drug regimen. Also, prior to allogeneic HSCT, building bridges to decitabine can be used for transplantation. At present, another common AzaC methylation inhibitor is thought to be decitabine with a similar efficacy; methylation of decitabine is considered to be more than ten times higher than that of $\mathrm{AzaC}$, so AzaC tolerance should be used in patients with decitabine. To summarize, decitabine is suitable for those high-risk patients who are 1) unable to undergo intensive chemotherapy; 2) unable to undergo allogeneic HSCT, performed before transplantation therapy; 3) relapsed after HSCT. Additionally, decitabine may also be applied to the low-risk patients with progressive increase of serum erythropoietin and/ or without secondary anemia.

\section{Use of decitabine as a monotherapy in the People's Republic of China}

Chinese hematologists have formed a basic consensus with respect to monotherapy with decitabine in the treatment of

Table 3 Prognosis of MDS according to WPSS risk score

\begin{tabular}{llll}
\hline WPSS & $\begin{array}{l}\text { Sum of individual } \\
\text { variable scores }\end{array}$ & $\begin{array}{l}\text { Median survival }(\mathbf{y}) \\
\text { from diagnosis }\end{array}$ & $\begin{array}{l}\text { Median time }(\mathbf{y}) \text { to AML } \\
\text { progression from diagnosis }\end{array}$ \\
\hline Very low & 0 & 11.6 & Not reached \\
Low & 1 & 9.3 & 14.7 \\
Intermediate & 2 & 5.7 & 7.8 \\
High & $3-4$ & 1.8 & 1.8 \\
Very high & $5-6$ & 1.1 & 1 \\
\hline
\end{tabular}

Abbreviations: MDS, myelodysplastic syndrome; WPSS, World Health Organization-based Prognostic Scoring System; AML, acute myeloid leukemia; $y$, years. 
MDS; the efficacy of 5 days of treatment of middle- and high-risk MDS has been confirmed and compared with chemotherapy, and it has been found to be more satisfactory for older patients who cannot have HSCT and long-term treatments.

Lv retrieved data on $60 \mathrm{MDS}$ patients receiving hospital treatment. ${ }^{47}$ Analysis of treatment efficacy in the decitabine treatment group and the control group showed an overall efficacy rate of $80 \%$ for the former, while the control group only showed $30 \%$. The rate of complete remission in the experimental group was $50 \%$, far higher than the control group's $6.67 \%$; there were six patients with disease in the test group, which was significantly lower than the 21 people in the control group. In a group treated with low doses, there was greater efficacy and no significant adverse reactions. However, the experimental data derived from the 5- and 3-day treatment scenarios do not compare.

Yang et $\mathrm{al}^{48}$ conducted a retrospective study on the efficacy of decitabine in 12 patients with MDS and MDS-AML. The results showed that out of the 12 patients, there was partial remission in one, steady progress in five, one severe case, and three deaths. There was a $66.67 \%$ rate of disease control (8/12), with an efficacy rate of $25 \%(3 / 12)$. The median survival of patients was $11.5( \pm 2.1)$ months, with a 1 -year overall survival rate of $40 \%$, and a 2 -year overall survival rate of $16.7 \%$; some MDS patients with leukemia even achieved complete remission, and there were fewer adverse reactions than in the 3-day scheme or 5-day scheme. As the sample size of this study was only 12, it is difficult to draw firm conclusions from it; further studies are required with larger sample sizes.

For medium- and high-risk MDS patients, the prognosis is relatively poor, and this may relate to abnormal DNA methylation, resulting in inactivation of the cancer suppressor gene. Low-dose decitabine methylates and reverses abnormal DNA methylation to induce the differentiation of tumor cells into normal cells, resulting in the apoptosis of tumor cells. Wang et $\mathrm{al}^{49}$ observed 12 cases of clinical efficacy and adverse reactions in patients with high-risk MDS treated using decitabine. The results showed that by using a low dose for 5 days, the longer course results in a higher chance of survival of MDS patients, but there is a bone marrow suppression ratio of $83.3 \%(10 / 12)$. This research indicated that with a 5-day, low-dose regimen for treating patients with high-risk MDS, survival rates are high, but the bone marrow suppression with therapeutic doses still requires optimization.

Overall, the domestic application of low-dose decitabine in the treatment of high-risk MDS has a significant effect, but its side effects are mainly stage III-IV and include infection in bone marrow transplantations. The treatment process needs to be enhanced by combining it with other drugs, use of antibiotics, blood transfusions, and HSCT in order to reduce the incidence of bone marrow transplantations and infections.

\section{Decitabine in combination with domestic drugs Combining with cytotoxic drugs}

MDS patients include a high proportion of elderly patients, due to its complicated history, associated organ dysfunction, immune dysfunction, and subsequent vulnerability to severe infections and bleeding, all of which give patients poor tolerance to chemotherapy and an inability to tolerate standarddose chemotherapy. Cao et $\mathrm{al}^{50}$ applied decitabine combined with a half-dose regimen of CAG for the treatment of MDS, and achieved a better overall efficacy rate of 75\% (6/8), suggesting that this reduces chemotherapeutic CAG doses, and so reduces the side effects of chemotherapy. ${ }^{51,52}$

Guan et $\mathrm{al}^{52}$ compared decitabine combined with HAG/ IAG (idarubicin/Ara-C/G-CSF) and a half-weight with a traditional CAG scheme; the overall efficacy rate of the former treatment reached $84.62 \%$, and overall survival was $36.2( \pm 11.8)$ months, with no adverse effects.

Overall, combination therapy can improve efficacy and reduce the incidence of adverse reactions, but bone marrow transplants remained higher, possibly because decitabine drug combinations are still strongly cytotoxic. This requires further research into other combination therapy programs.

\section{Combining with other epigenetic drugs}

Azacitidien and decitabine are the widely used DNA cytosine hypomethylation agents. Decitabine plays a major role in DNA, while azacitidine plays a major in both mRNA and DNA. ${ }^{53}$ Preliminary studies have suggested that decitabine is a ten times stronger hypomethylating agent than azacitidine, and that decitabine is safe for elderly patients. This has been confirmed by a number of clinical trials, but azacitidine without bone marrow toxicity is thought to be safer for elderly patients. Decitabine and azacitidine have been suggested for "advanced treatment", but the necessity for and feasibility of "bridge therapy" require further research.

\section{Combined immunotherapy}

Studies have revealed that decitabine is valid for MDS treatment and delays transformation to AML, but due to the bone 
marrow toxicity conferred by regular doses of decitabine, its application is restricted, especially in elderly patients. For elderly patients with MDS, this is the most commonly used treatment, but it has resulted in the need for treatment of severe bone marrow suppression. In preliminary clinical studies, Yang et $\mathrm{al}^{54}$ found that autologous cytokine-induced killer cells can cause some elderly MDS-AML patients to improve hematologically, even though the response may be partial. Consideration should be given to decitabine's potential role, through epigenetics, in regulation and control of the treatment of leukemia and cytokine-induced killercell-specific targeting of leukemia cells. Combining these could reduce the dose of decitabine required and improve efficacy.

\section{Integrated Chinese and Western medicine}

In traditional Chinese medicine (TCM), MDS is considered to belong to the categories of "consumptive diseases", "blood troubles", and "subcutaneous nodule"; the basic pathogenesis is that of "kidney essence deficiency, heat-toxin stagnation". ${ }^{55,56}$ Kidney dominates bone, and bone marrow stores up essence, which five internal organs measure; kidney essence deficiency causes heat-toxin connotations' deficiency and tuberculosis. The predominant treatment of MDS in TCM is restoring qi (the energy of life) and radical therapy, supported by blood-activating and stasis-resolving medicinal, antipyretic-detoxicate drugs or anticancer agent according to the malignant degree and clinical classification of the primary disease. ${ }^{57-59}$

Based on the diseases and syndrome differentiation treatment, Zhu et $\mathrm{al}^{60}$ optimized Chinese herbal prescription, utilizing "dissipating dampness and detoxication, supplementing qi and nourishing yin" as a basic principle. The traditional Chinese medicine can significantly reduce the adverse events of decitabine treatment, and contribute to the maintenance of vital signs stable organ function. Its safety and efficacy in MDS have bee confirmed (Table 4).

Results of research confirmed that many heat-clearing and detoxifying drugs working on interleukin-2 and tumor necrosis factor can promote efficacy, so the antitumor effect of Chinese medicine may occur by promoting the antitumor immune responses in the body. ${ }^{46}$

For patients with high-risk MDS, combined treatment with decitabine and TCM can significantly reduce adverse drug reactions and complications, and is safe and sustainable. The composition of TCM is complex, and so further studies of the combined mechanism, as well as clinical trials, are needed in order to consolidate the foundation for this combined treatment of MDS.

\section{Perspectives on decitabine for future applications}

To summarize, as a first-line drug for the treatment of MDS, decitabine has been widely applied as a single clinical drug, while significant results from drug combination therapies for the treatment of MDS have been obtained and unanimously endorsed by clinicians and patients. However, in the People's Republic of China, use of decitabine for the treatment of MDS still requires improvement; the current recommended treatment program is based upon Western clinical tests/trials and Western medical systems. This is unsuitable for domestic patients; reduced bone marrow caused by use of decitabine and further enhancement of decitabine's clinical cure rate are still key issues for doctors and patients. There is no thorough standard for decitabine application conditions or dosage, and no normative standardization training in grassroot hospitals.

Therefore, on the basis of national conditions and the characteristics of MDS, overall planning for the domestic treatment of MDS is necessary with the organization of a national multicenter, where clinical trials can be unified and treatments obtained. A multicenter clinical trial can collect more subjects over a relatively short period of time, and cover wide-ranging aspects of MDS and its treatment. This avoids the limitations of single studies and improves the design, execution, and analysis of clinical trials in order to obtain thorough, reasonable normalization standards. ${ }^{46}$

Additionally, with the promotion of basic research and clinical studies, it is expected that the real "epigenetic therapy" concept of a new dosage regimen, as well as combination therapies based on this concept, will be found. ${ }^{46}$

Table 4 Clinical observations of Chinese herbal medicine combined with decitabine in the treatment of high-risk MDS

\begin{tabular}{|c|c|c|c|c|c|c|}
\hline Group & $\begin{array}{l}\text { Complete } \\
\text { remission }\end{array}$ & Mitigation & $\begin{array}{l}\text { Hematologic } \\
\text { improvement }\end{array}$ & $\begin{array}{l}\text { Stable } \\
\text { condition }\end{array}$ & $\begin{array}{l}\text { Disease } \\
\text { progression }\end{array}$ & Efficacy \\
\hline $\begin{array}{l}\text { Traditional Chinese } \\
\text { medicine group ( } 16 \text { people) }\end{array}$ & $18.75 \%(3 / 16)$ & $18.75 \%(3 / 16)$ & $18.75 \%(3 / 16)$ & $6.25 \%(1 / 16)$ & $3.75 \%(6 / 16)$ & $56.25 \%(9 / 16)$ \\
\hline $\begin{array}{l}\text { Western medicine } \\
\text { group (I4 people) }\end{array}$ & $25.00 \%(3 / / 4)$ & $25.00 \%(2 / 14)$ & $41.67 \%(3 / 14)$ & $0.00 \%(0 / 14)$ & $8.33 \%(6 / 14)$ & $57.14 \%(8 / 14)$ \\
\hline
\end{tabular}

Abbreviation: MDS, myelodysplastic syndrome. 


\section{Acknowledgments}

This study was supported by the grants from the National Natural Science Foundation of China (Nos 81230061, 31270820,81272867 ) and was partially supported by Beijing Nova Program (Z131107000413103).

\section{Disclosure}

The authors report no conflicts of interest in this work.

\section{References}

1. Tormo M, Marugan I, Calabuig M. Myelodysplastic syndromes: an update on molecular pathology. Clin Transl Oncol. 2010;12(10):652-661.

2. Ornstein MC, Mukherjee S, Sekeres MA. More is better: combination therapies for myelodysplastic syndromes. Best Pract Res Clin Haematol. 2015;28(1):22-31.

3. Lv L, Lin G, Gao X, et al. Case-control study of risk factors of myelodysplastic syndromes according to World Health Organization classification in a Chinese population. Am J Hematol. 2011;86(2):163-169.

4. Kuang S, Liang W. Clinical analysis of 43 cases of chronic benzene poisoning. Chem Biol Interact. 2005;153-154:129-135.

5. Kuendgen A, Lubbert M. Current status of epigenetic treatment in myelodysplastic syndromes. Ann Hematol. 2008;87(8):601-611.

6. Navada SC, Steinmann J, Lubbert M, Silverman LR. Clinical development of demethylating agents in hematology. J Clin Invest. 2014;124(1):40-46.

7. Kelly TK, De Carvalho DD, Jones PA. Epigenetic modifications as therapeutic targets. Nat Biotechnol. 2010;28(10):1069-1078.

8. Cashen AF, Schiller GJ, O'Donnell MR, DiPersio JF. Multicenter, phase II study of decitabine for the first-line treatment of older patients with acute myeloid leukemia. J Clin Oncol. 2010;28(4):556-561.

9. Wee S, Dhanak D, Li H, et al. Targeting epigenetic regulators for cancer therapy. Ann N Y Acad Sci. 2014;1309:30-36.

10. Haladyna JN, Yamauchi T, Neff T, Bernt KM. Epigenetic modifiers in normal and malignant hematopoiesis. Epigenomics. 2015;7(2): 301-320.

11. Juo YY, Gong XJ, Mishra A, et al. Epigenetic therapy for solid tumors: from bench science to clinical trials. Epigenomics. 2015;7(2): 215-235.

12. Azad N, Zahnow CA, Rudin CM, Baylin SB. The future of epigenetic therapy in solid tumours - lessons from the past. Nat Rev Clin Oncol. 2013;10(5):256-266.

13. Huang YW, Kuo CT, Stoner K, Huang TH, Wang LS. An overview of epigenetics and chemoprevention. FEBS Lett. 2011;585(13):2129-2136.

14. Bejar R, Steensma DP. Recent developments in myelodysplastic syndromes. Blood. 2014;124(18):2793-2803.

15. Estephan F, Tiu RV. Current and novel therapeutic approaches in myelodysplastic syndromes. J Community Support Oncol. 2014;12(7): 236-249.

16. Ishikawa $T$. Novel therapeutic strategies using hypomethylating agents in the treatment of myelodysplastic syndrome. Int J Clin Oncol. 2014;19(1):10-15.

17. Gurion R, Vidal L, Gafter-Gvili A, et al. 5-azacitidine prolongs overall survival in patients with myelodysplastic syndrome - a systematic review and meta-analysis. Haematologica. 2010;95(2):303-310.

18. Xie M, Jiang Q, Xie Y. Comparison between decitabine and azacitidine for the treatment of myelodysplastic syndrome: a meta-analysis with 1,392 participants. Clin Lymphoma Myeloma Leuk. 2015;15(1):22-28.

19. Xu J,Zhou Y,Zhang J, et al. High incidence of severe neutropenia after gemcitabine-based chemotherapy in Chinese cancer patients with CDA 79A >C mutation. Clin Chim Acta. 2012;413(15-16):1284-1287.

20. Sugiyama E, Kaniwa N, Kim SR, et al. Pharmacokinetics of gemcitabine in Japanese cancer patients: the impact of a cytidine deaminase polymorphism. J Clin Oncol. 2007;25(1):32-42.
21. Iyer SN, Ankala A, Singhal RS, Hegde MR. Determination of common genetic variants in cytidine deaminase (CDA) gene in Indian ethnic population. Gene. 2013;524(1):35-39.

22. Ebrahem Q, Mahfouz RZ, Ng KP, Saunthararajah Y. High cytidine deaminase expression in the liver provides sanctuary for cancer cells from decitabine treatment effects. Oncotarget. 2012;3(10): $1137-1145$.

23. Mahfouz RZ, Jankowska A, Ebrahem Q, et al. Increased CDA expression/activity in males contributes to decreased cytidine analog half-life and likely contributes to worse outcomes with 5-azacytidine or decitabine therapy. Clin Cancer Res. 2013;19(4):938-948.

24. Lee YG, Kim I, Yoon SS, et al. Comparative analysis between azacitidine and decitabine for the treatment of myelodysplastic syndromes. Br J Haematol. 2013;161(3):339-347.

25. Oki Y, Kondo Y, Yamamoto K, et al. Phase I/II study of decitabine in patients with myelodysplastic syndrome: a multi-center study in Japan. Cancer Sci. 2012;103(10):1839-1847.

26. Uchida T, Ogawa Y, Kobayashi Y, et al. Phase I and II study of azacitidine in Japanese patients with myelodysplastic syndromes. Cancer Sci. 2011;102(9):1680-1686.

27. Musolino C, Sant'antonio E, Penna G, et al. Epigenetic therapy in myelodysplastic syndromes. Eur J Haematol. 2010;84(6):463-473.

28. Santos FP, Kantarjian H, Garcia-Manero G, Issa JP, Ravandi F. Decitabine in the treatment of myelodysplastic syndromes. Expert Rev Anticancer Ther. 2010;10(1):9-22.

29. Bryan J, Kantarjian H, Garcia-Manero G, Jabbour E. Pharmacokinetic evaluation of decitabine for the treatment of leukemia. Expert Opin Drug Metab Toxicol. 2011;7(5):661-672.

30. Saunthararajah Y, Sekeres M, Advani A, et al. Evaluation of noncytotoxic DNMT1-depleting therapy in patients with myelodysplastic syndromes. J Clin Invest. 2015;125(3):1043-1055.

31. Momparler RL. Pharmacology of 5-aza-2'-deoxycytidine (decitabine). Semin Hematol. 2005;42(3 Suppl 2):S9-S16.

32. Seymour JF, Fenaux P, Silverman LR, et al. Effects of azacitidine compared with conventional care regimens in elderly $(>/=75$ years $)$ patients with higher-risk myelodysplastic syndromes. Crit Rev Oncol Hematol. 2010;76(3):218-227.

33. Fenaux P, Mufti GJ, Hellstrom-Lindberg E, et al. Efficacy of azacitidine compared with that of conventional care regimens in the treatment of higher-risk myelodysplastic syndromes: a randomised, open-label, phase III study. Lancet Oncol. 2009;10(3):223-232.

34. Christiansen DH, Andersen MK, Pedersen-Bjergaard J. Methylation of p15INK4B is common, is associated with deletion of genes on chromosome arm $7 \mathrm{q}$ and predicts a poor prognosis in therapyrelated myelodysplasia and acute myeloid leukemia. Leukemia. 2003;17(9):1813-1819.

35. Kantarjian H, Issa JP, Rosenfeld CS, et al. Decitabine improves patient outcomes in myelodysplastic syndromes: results of a phase III randomized study. Cancer. 2006;106(8):1794-1803.

36. Lubbert M, Wijermans P, Kunzmann R, et al. Cytogenetic responses in high-risk myelodysplastic syndrome following low-dose treatment with the DNA methylation inhibitor 5-aza-2'-deoxycytidine. Br J Haematol. 2001;114(2):349-357.

37. Wijermans P, Lubbert M, Verhoef G, et al. Low-dose 5-aza-2'deoxycytidine, a DNA hypomethylating agent, for the treatment of high-risk myelodysplastic syndrome: a multicenter phase II study in elderly patients. J Clin Oncol. 2000;18(5):956-962.

38. Saba H, Rosenfeld C, Issa JP, et al. First report of the phase III North American trial of decitabine in advanced myelodysplastic syndrome (MDS). Blood. 2004;104:23a.

39. Yee KW, Jabbour E, Kantarjian HM, Giles FJ. Clinical experience with decitabine in North American patients with myelodysplastic syndrome. Ann Hematol. 2005;84(Suppl 1):18-24.

40. van den Bosch J, Lubbert M, Verhoef G, Wijermans PW. The effects of 5-aza-2'-deoxycytidine (Decitabine) on the platelet count in patients with intermediate and high-risk myelodysplastic syndromes. Leuk Res. 2004;28(8):785-790. 
41. Saba H, Lubbert M, Wijermans PW. Response rates of phase 2 and phase 3 trials of decitabine (DAC) in patients with myelodysplastic syndromes (MDS). Blood. 2005;106:706a.

42. Hu QJ, Chen BA. Recent advances in therapy of myelodysplastic syndromes. Zhongguo Shi Yan Xue Ye Xue Za Zhi. 2012;20(6): $1522-1525$.

43. Visconte V, Tiu RV, Rogers HJ. Pathogenesis of myelodysplastic syndromes: an overview of molecular and non-molecular aspects of the disease. Blood res. 2014;49(4):216-227.

44. Li J, Chen Y, Zhu Y, et al. Efficacy and safety of decitabine in combination with G-CSF, low-dose cytarabine and aclarubicin in newly diagnosed elderly patients with acute myeloid leukemia. Oncotarget. 2015;6(8):6448-6458.

45. Greenberg PL, Attar E, Bennett JM, et al. NCCN clinical practice guidelines in oncology: myelodysplastic syndromes. J Natl Compr Canc Netw. 2011;9(1):30-56.

46. Xiao Z. Decitabine in myelodysplastic syndromes: the current status and future. Zhonghua Xue Ye Xue Za Zhi. 2014;35(3):185-186.

47. Lv Z. Clinical efficacy of low-dose demethylation treatment of myelodysplastic syndrome. Mudanjiang Yi Xue Yuan Xue Bao. 2014; 35(3):47-48.

48. Yang H, Zhu HY, Jiang MM, et al. Clinical observation of decitabinetreating patients with myelodysplastic syndrome and acute myeloid leukemia. Zhongguo Shi Yan Xue Ye Xue Za Zhi. 2013;21(1):121-125.

49. Wang H, Wu Y, Ge S, Liu X. Therapeutic effect of decitabine in treating middle and high risk myelodysplastic syndrome. Zhi Ye Wei Sheng Yu Bing Shang. 2014;29(2):108-110.

50. Cao H, Wang Z, Lu XZS, Wu Z. Clinical research of patients with myelodysplastic syndromes and acute myeloid leukemia treated by decitabine with half quantity of CAG/CAO. Zhongguo Yi Xue Chuang Xin. 2014;11(31):131-133.

51. Zhang X, Deng Y, Zhang L, et al. Four case reports of sequential regimen of decitabine followed by half standard dose CAG in myelodysplastic syndrome and leukemic transformation. Bai Xi Bao Lin Ba Liu. 2012;21(7):433-435.
52. Guan J, Jiang Y, Sun A, et al. [Effect of decitabine in combination with $\mathrm{HAG} / \mathrm{IAG}$ regimen on elderly patients with AML and higher-risk MDS]. Zhong Hua Lin Chuang Yi Shi Za Zhi. 2014;8(21):3897-3900. Chinese.

53. Chen Q, Zhao L, Ling C. Efficacy and safety of demethylation agents for middle/high-risk patients with myelodysplastic syndrome: a systematic review. Zhongguo Xun Zheng Yi Xue Za Zhi. 2014;14(9):1097-1103.

54. Yang B, Cai L, Wang H, et al. Treatment of an elderly patient with acute myelocytic leukemia transformed from myelodysplastic syndrome with decitabine in ultra-low dosage combining with transfusion of autologous cytokineinduced killer cells: a case report and review of literature. Jie Fang Jun Yi Xue Za Zhi. 2014;39(4):315-319.

55. Xiao Y, Feng J. Research progress of traditional Chinese Medicine on myelodysplastic syndrome. Zhong Yi Yao Xin Xi. 2005;22(4):17-19.

56. Wu H. Practical Traditional Chinese Hematology. 2nd ed. Shanghai, People's Republic of China: Shanghai University of Traditional Chinese Medicine Press. 1996.

57. Huang Z, Qiu Z, Chen P, et al. Chinese medicine treatment of MDS staging clinical experience. Zhong Yi Wen Xian Za Zhi. 2007;25(3): 33-35.

58. Sun W, Meng X. Advances in the combined treatment of myelodysplastic syndrome with traditional Chinese and western medicine. Zhong Yi Yao Xin Xi. 2007;24(6):12-14.

59. Zhang H, Ma J. Comparison of traditional Chinese and western medicine treatment of myelodysplastic syndrome. Zhongguo Xian Dai Yi Sheng. 2008;46(21):71-85.

60. Zhu X, Qiu Z, Chen P, Zhao L, Huang Z, Hu X. Clinical efficacy of chinese medicine combined with decitabine in treatment of high risk myelodysplastic syndromes. Zhong Hua Zhong Yi Yao Xue Kan. 2014;32(5):1240-1243.
OncoTargets and Therapy

\section{Publish your work in this journal}

OncoTargets and Therapy is an international, peer-reviewed, open access journal focusing on the pathological basis of all cancers, potential targets for therapy and treatment protocols employed to improve the management of cancer patients. The journal also focuses on the impact of management programs and new therapeutic agents and protocols on

\section{Dovepress}

patient perspectives such as quality of life, adherence and satisfaction The manuscript management system is completely online and includes a very quick and fair peer-review system, which is all easy to use. Visit http://www.dovepress.com/testimonials.php to read real quotes from published authors. 